\title{
Recurrent Thyroid Gland Medullary Carcinoma
}

National Cancer Institute

\section{Source}

National Cancer Institute. Recurrent Thyroid Gland Medullary Carcinoma. NCI Thesaurus. Code C153623.

The reemergence of thyroid gland medullary carcinoma after a period of remission. 